Canadian

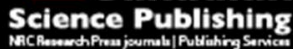

Canadian Geotechnical Journal Revue canadienne de géotechnique

\title{
Examination of the estimation of relative permeability for unsaturated soils
}

\begin{tabular}{|r|l|}
\hline Journal: & Canadian Geotechnical Journal \\
\hline Manuscript ID: & cgj-2015-0043.R2 \\
\hline Manuscript Type: & Article \\
\hline Complete List of Authors: & $\begin{array}{l}\text { Zhang, Feixia; University of Alberta, Department of Civil and } \\
\text { Environmental Engineering } \\
\text { Fredlund, Delwyn; Golder Associates Ltd., Saskatoon, }\end{array}$ \\
\hline Keyword: & $\begin{array}{l}\text { Permeability function, unsaturated coefficient of permeability, soil suction, } \\
\text { unsaturated soil property functions, air-entry value }\end{array}$ \\
\hline \multicolumn{2}{|c}{} \\
\hline
\end{tabular}




\section{Examination of the estimation of relative permeability for unsaturated soils}

Feixia Zhang ${ }^{1}$, and D.G. Fredlund ${ }^{2}$

${ }^{1}$ PhD Candidate, University of Alberta, Edmonton, AB, feixia@ualberta.ca

2 Senior Geotechnical Engineer, Golder Associates Ltd., Saskatoon, SK., Canada, unsaturatedsoil@yahoo.com

Corresponding author: Feixia Zhang

Address: Department of Civil \& Environmental Engineering, University of Alberta, Markin/CNRL Natural Resources Engineering Facility, $9105-116^{\text {th }}$ ST, Edmonton, Alberta, Canada, T6G 2W2 Telephone number: 780-708-5323

E-mail Address: feixia@ualberta.ca 


\section{Abstract:}

The unsaturated permeability function is an important soil property function used in the numerical modeling of saturated-unsaturated soil systems. The permeability function is generally predicted by integrating along the soil-water characteristic curve (SWCC) starting at saturated soil conditions. The integration is based on a particular integral formula. The Fredlund-Xing-Huang permeability function is a flexible integration techniques used for calculating the unsaturated permeability function. The original permeability theory published by Fredlund et al., (1994) specified that the air-entry value, $\psi_{\text {aev }}(\mathrm{AEV})$, be used as the lower limit of the integration when calculating the permeability function. However, since there was no analytical procedure available for the calculation of the air-entry value on the SWCC, it became common practice to start the integration procedure from a value near zero. The assumption was made that the error associated with starting the integration from an arbitrary low value was minimal. While this might be the case in some situations, the error can be quite substantial in other situations. This paper undertakes a study of the effect of the lower limit of integration on the calculation of the permeability function. Comparisons are made between starting the integration from various values below the AEV and starting the integration from the calculated air-entry value, $\psi_{\text {aev }}$ A mathematical algorithm is also proposed for the calculation of the AEV for integration purposes. The results show that the relative coefficient of permeability can be significantly under-estimated when the lower limit of integration is smaller than the AEV. The recommendation is that the AEV always be used as the lower limit of integration in the Fredlund-Xing-Huang permeability equation.

Key words: Permeability function, unsaturated coefficient of permeability, soil suction, unsaturated soil property functions, air-entry value. 


\section{Introduction}

The unsaturated coefficient of permeability function is required when modeling saturatedunsaturated soil systems. Direct measurement of the unsaturated permeability function is costly, technically-demanding, and time-consuming. As a result, the measurement of the unsaturated permeability function is reserved for research studies or large projects where substantial risk may be involved. Considerable research has been directed towards the estimation of the unsaturated coefficient of permeability function. There are four categories of models used for the estimation of unsaturated coefficient of permeability functions (Fredlund et al, 2012); namely, i.) empirical models, ii.) statistical models, iii.) correlation models and iv.) regression models. Empirical models and statistical models appear to be most extensively used in geotechnical engineering. The past decades have witnessed a rapid increase in the combined modeling of the saturated-unsaturated portions as a soil continuum (Fredlund et al. 2012). Considerable effort is expended in measuring the saturated coefficient of permeability of each soil layer and then the unsaturated soil permeability functions are generally estimated based on one of the above-mentioned models. Often the numerical modeling is followed by a parametric study or a probabilistic analysis which quantifies the effect of variations in the permeability function on the final outcome of the analysis. In any case, the estimation of the permeability function has become an integral part of assessing the hydraulic soil properties associated with seepage analyses.

Empirical models utilize the similar character of the soil-water characteristic curve, (SWCC), and the permeability function to estimate the unsaturated coefficient of permeability function. The Brooks and Corey (1964) equation is one example of an empirical model. Statistical models make use of the fact that the permeability function and the soil-water characteristic curve are mainly controlled by the pore-size distribution of the soil. Consequently, the permeability function was developed based on the interpretation and application of the SWCC. Childs and 
Collis-George (1950), Burdine (1953) and Mualem (1976) are three commonly used integral formulas of relative permeability based on different physical models.

The van Genuchten equation (1980) and the Fredlund and Xing equation (1994) are two wellknown mathematical equations for the SWCC. The van Genuchten SWCC equation was introduced into the Burdine (1953) equation and the Mualem (1976) integral formulas to obtain a permeability function. This gave rise to two closed-form solutions for the unsaturated soil permeability equation. The Fredlund and Xing (1994) SWCC equation was also introduced into the Childs and Collis-George (1950) integral formula, yielding an integral solution for the permeability equation. These combinations have given rise to three unsaturated soil permeability functions commonly used in geotechnical engineering. The three methodologies for the relative permeability function are referred to as: i.) the van Genuchten-Burdine (1980) equation, ii.) the van Genuchten-Mualem (1980) equation, and iii.) the Fredlund, Xing and Huang (1994) permeability function. In each of the above cases, the unsaturated soil permeability function is obtained by combining the saturated coefficient of permeability and the relative coefficient of permeability. The Fredlund, Xing and Huang (1994) permeability function has the advantage that the integral permeability function retains the independence of the SWCC fitting variables when estimating the coefficients of permeability. On the other hand, the van Genuchten permeability functions are closed-form and simpler to use in engineering practice.

The original relative permeability theory published by Fredlund et al., (1994) specified the airentry value, $\psi_{\text {aev }}$, as the lower limit of the integration. However, implementations in engineering practice appear to have used other values between zero and $\psi_{\text {aev }}$ as the starting point of integration when calculating the relative coefficient of permeability. It does not appear that any study has been undertaken to assess whether the choice for the lower limit of integration influences the calculation of the Fredlund, Xing and Huang (1994) permeability function. 
This paper investigates the error caused by using various values for the lower limit of integration. The effect of the lower limit of integration is examined in terms of the effect of each of the SWCC fitting parameters, (i.e., " $a_{f}, n_{f}, m_{f}, m_{f}$ "), on the resulting error. An empirical procedure for the determination of the air-entry value is also described. The definition of the "permeability error" is described followed by a study of the impact of the fitting parameters on the magnitude of the error in the permeability function.

\section{Determination of the Air-Entry Value (AEV) from the Degree of Saturation SWCC, (S- SWCC)}

The SWCC for a soil is defined as the relationship between the water content and soil suction (Williams 1982), and is commonly used as the basis for the estimation of unsaturated soil properties (e.g., the permeability function for an unsaturated soil). Different designations for the amount of water in the soil generate different forms of SWCC, such as gravimetric water content SWCC, volumetric water content SWCC, instantaneous volumetric water content SWCC, and degree of saturation SWCC. The volumetric water content is the water content with the volume of water referenced to the original total volume of the soil specimen. The instantaneous volumetric water content is the water content with the volume of water referenced to the instantaneous total volume of the soil specimen. Each form of the SWCC provides similar information to the geotechnical engineer if the soil does not undergo volume change as soil suction is increased. When soil undergoes volume change, as is the case for soft clays and slurry soils, the gravimetric water content SWCC, instantaneous volumetric water content SWCC and degree of saturation SWCC are distinctly different from one another. Volumetric water content SWCC is not of significance when soil undergoes high volume change. Conventional permeability functions (e.g., Fredlund et al. (1994) equation; van GenuchtenBurdine equation; van Genuchten-Mualem equation) produce reasonable estimations using 
volumetric water content SWCC when there is no volume change during drying. Volumetric water content SWCC is no longer appropriate in the estimation of the relative permeability function when soil undergoes volume change. It is important to know that the relative coefficient of permeability function, as well as the air-entry value must be estimated from degree of saturation SWCC (Fredlund et al. 2011). This paper uses the degree of saturation SWCC to calculate the appropriate estimation of the relative permeability function.

Various forms of mathematical equations have been suggested to characterize the SWCC. The equation proposed by Fredlund and Xing (1994) has been shown to have sufficient flexibility to best-fit laboratory data reasonably well over the entire soil suction range from near zero to $10^{6}$ $\mathrm{kPa}$ provided the material behaves in a mono-modal manner. The form of the Fredlund and Xing (1994) equation written in terms of degree of saturation, (i.e., S-SWCC) is shown in equation (1).

$$
S(\psi)=\frac{S_{0}\left(1-\ln \left(1+\psi / \psi_{r}\right) / \ln \left(1+10^{6} / \psi_{r}\right)\right)}{\left(\ln \left(\exp (1)+\left(\psi / a_{f}\right)^{n_{f}}\right)\right)^{m_{f}}}
$$

where,

$\psi=$ soil suction;

$S(\psi)=$ degree of saturation at a soil suction of $\psi$;

$S_{0}=$ initial degree of saturation at zero soil suction; and

$a_{f}, n_{f}, m_{f}, \psi_{r}=$ four best-fitting parameters controlling the shape of the SWCC.

The shape of the SWCC (e.g., described by the air-entry value, the slope, the residual conditions) are influenced by the four fitting parameters, (i.e., $a_{f}, n_{f}, m_{f}$ and $\psi_{f}$ ) in a combined 
and complex manner. There is no simple one-on-one connection between the fitting parameters and the features of the curve, although $a_{f}$ affects the air-entry value in a significant way, while $n_{f}$ significantly influences the slope of SWCC. Bharat and Sharma, (2012) studied the validity limits of of the Fredlund-Xing parameters and found that small values of $\psi_{r}$ influenced the SWCC near saturation and $m_{f}$ also influenced the residual portion of the SWCC. In other words, these variables affect the shape of an SWCC in a coupled manner.

The air-entry value, (AEV), of the soil is the suction at which air begins to enter the largest pores in the soil (Fredlund and Xing, 1994). Vanapalli et al., (1998) proposed an empirical, graphical construction technique to estimate the air-entry value from the SWCC. The air-entry value must be determined from the degree of saturation SWCC (Fredlund et al. 2011).

A mathematical algorithm is proposed in this paper for the determination of the AEV based on the graphical construction suggested by Vanapalli et al. (1998). The following steps are outlined with respect to the analysis for the AEV.

Step 1. Find the best-fitting SWCC for the degree of saturation SWCC using the Fredlund and Xing (1994) equation (Figure 1).

Step 2. Through use of a variable substitution technique, the Fredlund-Xing (1994) best-fitting equation can be transformed into a substitution equation (i.e., Eq. 2). The substitution equation describes the relationship between the degree of saturation and the logarithm of soil suction to the base 10 (Figure 2). The shape of the curve for the substitution equation plotted using arithmetic coordinates is the same as the shape of the curve for the best-fitting equation plotted 
using a semi-logarithmic coordinate system. The arithmetic plot of the substitution equation has the same inflection point as the semi-logarithmic plot of the best-fitting equation.

$$
S S(\xi)=\frac{S_{0}\left(1-\ln \left(1+10^{\xi} / \psi_{r}\right) / \ln \left(1+10^{6} / \psi_{r}\right)\right)}{\left(\ln \left(\exp (1)+\left(10^{\xi} / a_{f}\right)^{n_{f}}\right)\right)^{m_{f}}}
$$

where,

$\xi=\log _{10}(\psi) ; S S(\xi)=$ the degree of saturation at a soil suction of $\psi$;

$\psi=$ soil suction .

Step 3. Determine the point of maximum slope (or the inflection point) on the arithmetic plot of the substitution equation. The point of maximum slope is also a point of zero curvature. Therefore, the second derivative of equation (2) can be set equal to zero as shown in equation (3).

$$
\frac{\mathrm{d}^{2} S S(\xi)}{\mathrm{d} \xi^{2}}=0
$$

Solving equation (3) for the $\xi$ value of zero curvature point and substituting the $\xi$ value into equation (2) yields the corresponding term, $S S(\xi)$. The determined point of zero curvature has coordinates $\left(\xi_{i}, S S\left(\xi_{i}\right)\right)$ (Figure 2).

Step 4. Draw a line tangent to the curve through the point of maximum slope (Figure 2). The point of maximum slope is $\left(\xi_{i}, S S\left(\xi_{i}\right)\right)$ and the maximum slope is $S S^{\prime}\left(\xi_{i}\right)$. The equation for the tangent line is as shown in equation (4).

$$
T L(\xi)=S S^{\prime}\left(\xi_{i}\right)\left(\xi-\xi_{i}\right)+S S\left(\xi_{i}\right)
$$

Where, $T L(\xi)$ represents the function of the tangent line. 
Step 5. Draw a horizontal line through the maximum degree of saturation. The intersection of the two lines indicates the air-entry value (Figure 2). The horizontal line is given by equation (5).

$$
H L(\xi)=S_{0}
$$

Where, $H L(\xi)$ represents the function of the horizontal line.

The intersection point can be obtained mathematically by solving equations (5) and (4). The intersection point is, $\left(\frac{S_{0}-S S\left(\xi_{i}\right)}{S S^{\prime}\left(\xi_{i}\right)}+\xi_{i}, S_{0}\right)$, on the arithmetic plot.

Step 6. Back calculate the AEV through use of the relationship, $\xi=\log _{10}(\psi)$. The air-entry value for the soil can be written as follows.

$$
\psi_{A E V}=10^{\frac{S_{0}-S S\left(\xi_{i}\right)}{S S^{\prime}\left(\xi_{i}\right)}+\xi_{i}}
$$

\section{Statement of the Integration Problem Associated with the Fredlund, Xing and Huang (1994) Permeability Function}

Fredlund, Xing and Huang (1994) suggested a mathematical function for the estimation of the relative coefficient of permeability based on a physical model proposed by Childs and CollisGeorge (1950) (see equation (7)).

$$
k_{r}^{S}(\psi)=\frac{\int_{\ln (\psi)}^{b} \frac{S\left(e^{y}\right)-S(\psi)}{e^{y}} S^{\prime}\left(e^{y}\right) d y}{\int_{\ln \left(\psi_{\text {aev }}\right)}^{b} \frac{S\left(e^{y}\right)-S\left(\psi_{\text {aev }}\right)}{e^{y}} S^{\prime}\left(e^{y}\right) d y}
$$

Where,

$k_{r}^{s}(\psi)=$ relative coefficient of permeability at soil suction of $\psi$. The superscript $s$ means that the degree of saturation-SWCC is used for the estimation of the relative permeability in Equation (7); 
$b=$ upper limit of integration [i.e., $\ln (1000000)]$;

$y=$ dummy variable of integration representing the logarithm of suction;

$S=$ degree of saturation-SWCC equation;

$S^{\prime}=$ derivative of the degree of saturation-SWCC equation;

$e^{y}=$ natural number raised to the dummy variable power.

The denominator of equation (7) is an integral, the lower limit of the integration of which is the air-entry value, $\psi_{\text {aev }}$. Although the original theory (Fredlund et al, 1994) specified the air-entry value, $\psi_{\text {aev }}$, as the lower limit of integration, other values between a value close to zero and $\psi_{\text {aev }}$ have been used as the starting point for integration while estimating the relative permeability function. The arbitrarily selected small value for the starting point of integration appears to have been used because no closed-form analytical procedure had been proposed for the calculation of the AEV. Details on how the integration using Fredlund et al (1994) permeability is to be carried out can be found in the original paper. In addition, the importance of using the degree of saturation SWCC for calculating the permeability function has not been clearly emphasized in the research literature.

If a suction value $\psi_{i}$ between (near) zero and $\psi_{\text {aev }}$ is used as the lower limit of integration, the permeability function of equation (7) takes on the form shown in equation (8)

$$
k_{r i}^{S}(\psi)=\frac{\int_{\ln (\psi)}^{b} \frac{S\left(e^{y}\right)-S(\psi)}{e^{y}} S^{\prime}\left(e^{y}\right) d y}{\int_{\ln \left(\psi_{i}\right)}^{b} \frac{S\left(e^{y}\right)-S\left(\psi_{i}\right)}{e^{y}} S^{\prime}\left(e^{y}\right) d y}
$$

where, $k_{r i}^{s}(\psi)=$ relative coefficient of permeability at soil suction of $\psi$, when a suction value $\psi_{i}$ is used as the lower limit of integration for the integral in the denominator of the Equation (8). 
Childs and Collis-George (1950) proposed the use of a statistical model. There are three common assumptions for a methodology characterizing the statistical models: (a) The porous medium may be regarded as a set of interconnected pores randomly distributed in the sample. The pores are characterized by their length scale called "the pore radius". (b) The HagenPoiseuille equation is assumed valid at the level of the single pore and thus used to estimate the hydraulic conductivity of the elementary pore unit. The total hydraulic conductivity has to be determined by integration over the contributions of the filled pores. (c) The soil-water characteristic curve is considered analogous to the pore radius distribution function. The capillary law is used to uniquely relate the pore radius to the capillary head (Mualem, 1986). The air-entry value of the soil corresponds to the largest pore radius. The change of the lower limit integration implies a change in the largest pore radius of the soil and thus the change in the pore radius distribution function.

The relative coefficient of permeability obtained using equation (7) is theoretically correct and is used as the reference value in the present study. An error in the estimation of the relative permeability is introduced when using equation (8) along with a variety of the lower limits of integration in the denominator. The slope on the soil-water characteristic curve, (SWCC), prior to the AEV (as defined by the degree of saturation SWCC), contributes to the error in the computed permeability function.

The Fredlund, Xing and Huang (1994) permeability function was developed based on the interpretation of the SWCC. Figure 3 illustrates a situation where the effect of the starting point for integration is small. Starting integration at any point from $0.1 \mathrm{kPa}$ to the AEV results in the computation of essentially the same relative permeability function. Figure4, on the other hand, shows how the starting point for integration can have a significant effect on the computed 
permeability function. The difference between the results shown in Figures 3 and 4 appears to be mainly due to a change in the $n_{f}$ (or steepness of the SWCC) variable.

The shape of the SWCC greatly influences the errors that could be caused in the estimation results for the permeability function. Therefore, it is important to study the effect of each of the four fitting parameters $a_{f}, n_{f}, m_{f}, \psi_{r}$ on the errors in the permeability function that is introduced by using a small value as the lower limit of integration. The objective of this paper is to examine the effect of each of the fitting variables, $a_{f}, n_{f}, m_{f}, \psi_{r}$ on errors in the relative permeability function that is caused by using various small values for the lower limit of integration.

\section{Definition of the Error Introduced by Using an Inappropriate Lower Limit of Integration} $\operatorname{ERR}\left(\psi, \psi_{i}\right)$ is the mathematical function used to quantify the error introduced as a result of selecting various values for the lower limit of integration. More specifically, it is the change in permeability introduced by using equation (8) with a lower limit of integration other than the airentry value, $(\mathrm{AEV})$, in the denominator. The comparison is made to the permeability obtained when using equation (7) with the $\mathrm{AEV}$ as the lower limit of integration in the integral of denominator. The mathematical form of the error $\operatorname{ERR}\left(\psi, \psi_{i}\right)$ is given by equation (9). 


$$
\operatorname{ERR}\left(\psi, \psi_{i}\right)=\left\{\begin{array}{l}
\log _{10}\left(\int_{\ln \left(\psi_{i}\right)}^{b} \frac{S\left(e^{y}\right)-S\left(\psi_{i}\right)}{e^{y}} S^{\prime}\left(e^{y}\right) d y\right. \\
\int_{\ln (\psi)}^{b} \frac{S\left(e^{y}\right)-S(\psi)}{e^{y}} S^{\prime}\left(e^{y}\right) d y
\end{array}\right), 0<\psi<\psi_{i}<\psi_{\text {aev }}
$$

The error is defined in terms of orders of magnitude. $\operatorname{ERR}\left(\psi, \psi_{i}\right)$ in equation (9) is the common logarithm of the ratio of the permeability at any soil suction, $\psi$, estimated by equation (7) to the permeability estimated by equation (8) with $\psi_{i}$ set at various lower limits of integration in the denominator. The lower limit of integration $\psi_{i}$ in equation (8) is a suction value between the AEV and a lower suction. The definition of $\operatorname{ERR}\left(\psi, \psi_{i}\right)$ implies that the closer the value, $E R R\left(\psi, \psi_{i}\right)$ is to 0 , the smaller the error. The error $\operatorname{ERR}\left(\psi, \psi_{i}\right)$ remains at a constant value equal to $\operatorname{ERR}\left(A E V, \psi_{i}\right)$ for soil suctions greater than the AEV. $\operatorname{ERR}\left(A E V, \psi_{i}\right)$ is the upper bound of the error $\operatorname{ERR}\left(\psi, \psi_{i}\right)$ and it represents the largest error across the entire soil suction range when using various $\psi_{i}$ values as the lower limit of integration rather than the AEV in equation (8) when calculating the relative permeability. The error at the AEV, $E R R\left(A E V, \psi_{i}\right)$ rather than the error, $\operatorname{ERR}\left(\psi, \psi_{i}\right)$, across the entire suction range is studied in a parametric manner. Figure 5 illustrates the meaning of the error at the AEV, $\operatorname{ERR}\left(A E V, \psi_{i}\right)$ in terms of orders of magnitude caused by using $\psi_{i}$ as the lower limit of integration in equation (8). 
The sensitivity of $E R R\left(A E V, \psi_{i}\right)$ to changes in the best-fitting parameters, " $\boldsymbol{a}_{f}, \boldsymbol{n}_{f}, \boldsymbol{m}_{f}, \boldsymbol{\Psi}_{r}$ " for the SWCC

A parametric study was undertaken to investigate the empirical relationships between the bestfitting parameters " $a_{f}, n_{f}, m_{f}, \psi_{r}$ " of the SWCC and the error of $E R R\left(\psi, \psi_{i}\right)$, associated with the Fredlund et al. (1994) permeability function. The error at the AEV, $\operatorname{ERR}\left(A E V, \psi_{i}\right)$ rather than the error, $\operatorname{ERR}\left(\psi, \psi_{i}\right)$, across the entire suction range is studied for simplification. Table 1 summarizes the parametric study in matrix form.

\section{The influence of the $\boldsymbol{n}_{\boldsymbol{f}}$ value on $\operatorname{ERR}\left(A E V, \psi_{i}\right)$}

The sensitivity of the error in the permeability function at the AEV to the change of the $n_{f}$ value on the SWCC is studied for permeability functions obtained using equation (8). Seven different lower limits of integration $\psi_{i}$ were selected for the integral in the denominator. These seven different lower limits of integration are $10,4,2,1,0.5,0.2$ and $0.1 \log _{10}$ cycles less than the empirical AEV. Figure 6 and Figure 8 show the errors in the estimation of the relative coefficient of permeability caused by using various lower limits of integration when $a_{f}=10 \mathrm{kPa}$ and $a_{f}=100$ $\mathrm{kPa}$, respectively (Note: $n_{f}=1 ; m_{f}=1 ; \psi_{r}=2000 \mathrm{kPa}$ ).

The empirical relationships between $\operatorname{ERR}\left(A E V, \psi_{i}\right)$ and the corresponding $n_{f}$ value for various $\psi_{i}$ are plotted in Figure 7 and Figure 9. A value of 1 on the vertical coordinate refers to one order of magnitude change in the coefficient of permeability at the AEV, and a value of 4 would mean 4 orders of magnitude. Figure 7 reveals the influence of $n_{f}$ on the errors when $a_{f}=10 \mathrm{kPa}$; $m_{f}=1 ; \psi_{r}=2000 \mathrm{kPa}$. Figure 9 shows the influence of $n_{f}$ on the errors when $a_{f}=100 \mathrm{kPa} ; m_{f}=$ $1 ; \psi_{r}=2000 \mathrm{kPa}$. In Figures 6 to 9 , the curve denoted by SP1 in the legend is related to the 
error caused by using a value $4 \log _{10}$ cycles less than the empirical AEV as the lower limit of integration. The curve denoted by SP2 in the legend is for the error caused by using a lower limit of integration that is $2 \log _{10}$ cycles less than the empirical AEV. The other notations (e.g., SP3, SP4, SP5 and SP6) can be interpreted in the same way as interpreted for SP1 and SP2.

Figures 7 and 8 show a similar pattern when different $a_{f}$ values are selected. The results show the errors in the estimation of the relative permeability at the AEV when using equation (8) with different lower limits of integration $\psi_{i}$ instead of using equation (7) with the AEV as the starting integration point. The results in Figures 7 and Figure 8 reveal that the error decreases with an increase in the $n_{f}$ value, particularly when the $n_{f}$ value is smaller than 2 . The slope of the change of the error versus the $n_{f}$ value becomes much steeper at small $n_{f}$ values. This is particularly true for errors caused by using a lower limit of integration which is beyond $2 \log _{10}$ cycles less than the AEV. The results also show that using a value of more $\log _{10}$ cycles separated from the AEV as the lower limit of integration produces a greater error in the estimated permeability function for a particular SWCC. This phenomenon is more apparent when the $n_{f}$ value is smaller than 2 . In this case, the estimated relative permeability is significantly influenced by the selected lower limit of integration for a particular SWCC. It is important to use the correct lower limit of integration (i.e., the computed $\mathrm{AEV}$ ), in the estimation of the permeability function

Figures 10 present errors caused by using a lower limit of integration of $4 \log _{10}$ cycles less than the AEV for permeability functions obtained from SWCCs with various $a_{f}$ values. The purpose of arranging the results in this manner is to shows how the $a_{f}$ value affects the error in the estimation of the permeability function when an inappropriate lower limit of integration is used. The starting point for integration is denoted in terms of the $\log _{10}$ cycles less than the AEV. It was found that the $a_{f}$ value does not have much influence on the error caused by using the inappropriate lower limit of integration. However, the error is more sensitive to the $a_{f}$ value when 
it is combined with small $n_{f}$ values. Table 2 presents the range of the magnitude of the error in the estimation of permeability when the $n_{f}$ value changes from 0.5 to 12 , with $m_{f}=1$ and $\psi_{f}=$ $2000 \mathrm{kPa}$. The Table shows that if $a_{f}$ is equal to $1 \mathrm{kPa}$ and the integration starts from a value of $10 \log _{10}$ cycles less than the AEV, the error would range from 0.1 to 10 orders of magnitude when the $n_{f}$ value changes from 0.5 to 12 , respectively.

\section{The influence of the $\boldsymbol{m}_{\boldsymbol{f}}$ value on $\operatorname{ERR}\left(A E V, \psi_{i}\right)$}

The sensitivity of the error in the permeability function (at the AEV) to changes in the $m_{f}$ value is studied for permeability functions obtained using equation (8) with various lower limits of integration. The results are shown in Figures 11 to 13 . Figures 11 and 12 are for different $a_{f}$ values and show the errors in the estimation of permeability at AEV caused by using equation (8) with different lower limits of integration $\psi_{i}$ instead of the AEV. Figure 13 presents the errors in a different manner to show the effect of the $a_{f}$ value on the error in the estimation of the permeability function when an inappropriate lower limit of integration is used. The errors in the comparison at particular $m_{f}$ value are for permeability functions obtained from SWCCs with varying $a_{f}$ values.

The results show that the error caused by a lower limit of integration of several $\log _{10}$ cycles less than the AEV does not change much with changing $m_{f}$ values for the SWCCs. In other words, the $m_{f}$ value of the SWCC has limited influence on the errors in the estimation of the permeability function that may be caused by a low starting point of integration. The greater difference the lower limit of integration has from the AEV, the larger the error for the permeability function for a particular SWCC. Figures 13 shows also that the influence of the $a_{f}$ value of the SWCC having on the error is small when " $n_{f}, m_{f}, \psi_{r}$ " are fixed. The smaller the $a_{f}$ value, the less the error caused by using a lower limit of integration below the AEV. The 
influence of the $a_{f}$ value on the error is relatively apparent at small $m_{f}$ values. Table 3 shows the range of the magnitude of the error in the estimation of permeability when the $m_{f}$ value changes from 0.5 to 4 with $n_{f}=2$ and $\psi_{f}=2000 \mathrm{kPa}$.

\section{The influence of the " $\psi_{\boldsymbol{f}} / \mathbf{a}_{\boldsymbol{f}}$ " value on $\operatorname{ERR}\left(A E V, \psi_{i}\right)$}

The influence of the $\psi_{f} / a_{f}$ value on the error in the permeability function at the AEV was also studied using equation (8) with different lower limits of integration. The results show that the magnitude of the error caused by a small value for the lower limit of integration (i.e., $\log _{10}$ cycles less than the AEV) does not significantly change with the $\psi_{f} / a_{f}$ value except when the $\psi_{f}$ / $a_{f}$ value is smaller than 10 . Also, the influence of the $a_{f}$ value on the error is negligible.

\section{Comparison of the influences of the $n_{f}, m_{f}, \psi_{f} l a_{f}$ values on the magnitude of the error}

The error in terms of orders of magnitude caused by using an inappropriate lower limit of integration that is $10 \log _{10}$ cycles less than the AEV can vary from 0.1 to 10 when the $n_{f}$ value changes from 12 to 0.5 with $m_{f}=1, \psi_{f}=2000 \mathrm{kPa}$. The change in the magnitude of error is within 0.05 orders of magnitude when the $m_{f}$ value changes between 0.5 to 4 with $n_{f}=2, \psi_{f}=$ $2000 \mathrm{kPa}$. There is change of about 0.5 orders of magnitude in the error when the $\psi_{f} / a_{f}$ value changes from 1 to $1000 \mathrm{kPa}$ with $n_{f}=2, m_{f}=1 \mathrm{kPa}$.

The analysis reveals that the influence of the $n_{f}$ on the error caused by using too low a lower limit of integration is much greater than the influence of the $m_{f}$ and $\psi_{f} / a_{f}$ values. The $a_{f}$ has limited influence on the error. The lower the starting point of integration below the AEV is, the greater the calculation error.

\section{Conclusions}


Following is a summary of the conclusions that can be drawn from the study related to the starting point of integration for the Fredlund et al., (1994) permeability function.

I. If a lower limit of integration used in the integral of Fredlund et al (1994) is smaller than the $A E V$, the computed results will under-estimate the relative coefficient of permeability. The smaller the value used for the starting point of integration compared to the AEV, the greater will be the difference between the computed results and the relative permeability.

II. The error caused by using a small value for the lower limit of integration is influenced by the fitting parameters of the Fredlund-Xing (1994) SWCC equation, namely $a_{f}, n_{f}, m_{f}, \psi_{r}$. The analysis reveals that the influence of the $n_{f}$ value is much greater than the influence of $a_{f}, m_{f}$ and $\psi_{f} / a_{f}$ values.

III. The difference caused by a particular lower limit of integration, defined in terms of a particular number of $\log _{10}$ cycles less than the AEV, decreases with an increase in the $n_{f}$ value when the values of $a_{f}, m_{f}, \psi_{r}$ are fixed. This is particularly true when the $n_{f}$ value is smaller than 2.

IV. The $m_{f}$ value for the SWCC has limited influence on the difference in the estimation of the permeability function that may be caused by a low starting point of integration.

V. The difference in the estimation of the relative coefficient of permeability caused by using a particular low starting point of integration usually does not change much with the change in the $a_{f}$ value. However, the difference becomes more sensitive to the $a_{f}$ value when it is combined with a small $n_{f}$ values and small $m_{f}$ values. 
VI. It is recommended that the AEV always be used as the lower limit of integration when estimating the relative permeability function with the Fredlund et al., (1994) estimation procedure.

VII. Further studies regarding the importance of $\mathrm{AEV}$ in the estimation of the relative permeability function are recommended to be undertaken where other physical models are used along with other SWCCs.

\section{List of References}

Bharat, T. V., and Sharma, J. 2012. "Validity limits of Fredlund-Xing-Kunze model for the estimation of hydraulic properties of unsaturated soils", Proceddings of Canadian Geotechnical Conference, Winnipeg, Manitoba, September $30^{\text {th }}$ to October $3^{\text {rd }}$., paper \#263.

Brooks, R. H., and Corey, A. T. 1964. "Hydraulic properties of porous media". Colorado State University, (March) Hydraulic Paper No. 3, 27 p.

Burdine, N. 1952. "Relative permeability calculations from pore size distribution data". Transactions of the AIME, Vol. 198, pp. 71-77.

Childs, E. C., and Collis-George, N. 1950. "The permeability of porous materials". Proceedings of the Royal Society of London. Series A. Mathematical and Physical Sciences, 201(1066), pp. 392-405.

Mualem, Y., and Klute, A. 1986. "Hydraulic conductivity of unsaturated soils: prediction and formulas." Methods of Soils Analysis. Part 1. Physical and Mineralogical Methods, 799823.

Fredlund, D. G., and Xing, A. 1994. "Equations for the soil-water characteristic curve". Canadian Geotechnical Journal, 31(4), 521-532. 
Fredlund, D. G., Xing, A., and Huang, S. 1994. "Predicting the permeability function for unsaturated soils using the soil-water characteristic curve". Canadian Geotechnical Journal, 31(4), 533-546.

Fredlund, D. G., Stone, J., Stianson, J., and Sedgwick, A. 2011. "Determination of water storage and permeability functions for oil sands tailings". Proceedings of the Tailings and Mine Waste Conference, Vancouver, B.C..

Fredlund, D. G., Rahardjo, H., and Fredlund, M. D. 2012. “Unsaturated soil mechanics in engineering practice”. John Wiley \& Sons, New York, N.Y., 926 p.

Mualem, Y. 1976. "A new model for predicting the hydraulic conductivity of unsaturated porous media". Water Resources Research, 12(3), 513-522.

Van Genuchten, M. T. 1980. "A closed-form equation for predicting the hydraulic conductivity of unsaturated soils." Soil Science Society America Journal, 44(5), 892-898.

Vanapalli, S.K., Sillers, W.S., and Fredlund, M.D. 1998. "The meaning and relevance of residual state to unsaturated soils", Proceedings of the Fifty-First Canadian Geotechnical Conference, Edmonton, AB, October 4-7, pp.1-8.

Williams, P.J. 1982. "The surface of the Earth, an introduction to geotechnical science". Longman Inc., New York. 


\section{LIST OF FIGURES}

Figure 1. S-SWCC for a hypothetical soil plotted using semi-logarithmic coordinate

Figure 2. The arithmetical plot of the substitution equation

Figure 3. Relative coefficient of permeability obtained using equation (8) with different lower limits of integration for a soil with $a_{f}=500 \mathrm{kPa}, n_{f}=4, m_{f}=1, \psi_{r}=10,000 \mathrm{kPa}$ for SWCC

Figure 4. Relative coefficient of permeability obtained using equation (8) with different lower limits of integration for a soil with $a_{f}=500 \mathrm{kPa}, n_{f}=1, m_{f}=1, \psi_{r}=10000 \mathrm{kPa}$ for SWCC

Figure 5. Error at AEV in terms of orders of magnitude caused by using $\psi_{i}$ equal to $1 \mathrm{kPa}$ as the lower limit of integration in equation (8)

Figure 6 . The error in the estimation of the relative coefficient of permeability caused by various lower limits of integration $\left(a_{f}=10 \mathrm{kPa} ; n_{f}=1 ; m_{f}=1 ; \psi_{r}=2000 \mathrm{kPa}\right)$

Figure 7. The influence of $n_{f}$ on the errors caused by using various lower limits of integration

Figure 8. The error in the estimation of the relative coefficient of permeability caused by various lower limits of integration $\left(a_{f}=100 \mathrm{kPa} ; n_{f}=1 ; m_{f}=1 ; \psi_{r}=2000 \mathrm{kPa}\right)$

Figure 9. The influence of $n_{f}$ on the errors caused by using various lower limits of integration $\left(a_{f}\right.$ $\left.=100 \mathrm{kPa} ; m_{f}=1 ; \psi_{r}=2000 \mathrm{kPa}\right)$

Figure 10. The influence of $n_{f}$ on the errors caused by using a low lower limit of integration of 4 $\log _{10}$ cycles less than the AEV in cases of various $a_{f}$ values

Figure 11. The influence of $m_{f}$ on the errors caused by using various lower limits of integration $\left(a_{f}=10 \mathrm{kPa} ; n_{f}=2 ; \psi_{r}=2000 \mathrm{kPa}\right)$

Figure 12. The influence of $m_{f}$ on the errors caused by using various lower limits of integration $\left(a_{f}=100 \mathrm{kPa} ; n_{f}=2 ; \psi_{r}=2000 \mathrm{kPa}\right)$

Figure 13. The influence of $m_{f}$ on the errors caused by using a low lower limit of integration of 4 $\log _{10}$ cycles less than the AEV in cases of various $a_{f}$ values 


\section{LIST OF TABLES}

Table 1. Matrix of fitting parameters used in the parametric study

Table 2. Range of the magnitude of the error in the estimation of permeability when the $n_{f}$ value changes from 0.5 to $12 .\left(m_{f}=1 ; \psi_{f}=2000 \mathrm{kPa}\right)$

Table 3. Range of the magnitude of the error in the estimation of permeability when the $m_{f}$ value changes from 0.5 to $4 .\left(n_{f}=2 ; \psi_{f}=2000 \mathrm{kPa}\right)$ 
Table 1. Matrix of fitting parameters used in the parametric study.

\begin{tabular}{|c|c|c|c|c|c|}
\hline \multirow{2}{*}{ Figure \# } & \multicolumn{5}{|c|}{ Designated values } \\
\cline { 2 - 6 } & $n_{f}$ & $m_{f}$ & $a_{f}(\mathrm{kPa})$ & $\psi_{r}(\mathrm{kPa})$ & $\begin{array}{l}\text { Lower limit of integration (in terms } \\
\text { of Log }_{10} \text { cycles less than the AEV) }\end{array}$ \\
\hline Figure 6 & 1 & 1 & 10 & 2000 & various \\
\hline Figure 7 & $0.5-12$ & 1 & 10 & 2000 & various \\
\hline Figure 8 & 1 & 1 & 100 & 2000 & various \\
\hline Figure 9 & $0.5-12$ & 1 & 100 & 2000 & 4 \\
\hline Figure 10 & $0.5-12$ & 1 & various & 2000 & various \\
\hline Figure 11 & 2 & $0.5-4$ & 10 & 2000 & various \\
\hline Figure 12 & 2 & $0.5-4$ & 100 & 2000 & 4 \\
\hline Figure 13 & 2 & $0.5-4$ & various & 2000 & \\
\hline
\end{tabular}


Table 2. Range of the magnitude of the error in the estimation of permeability when the $n_{f}$ value changes from 0.5 to $12 .\left(m_{f}=1 ; \psi_{f}=2000 \mathrm{kPa}\right)$

\begin{tabular}{|c|c|c|c|c|c|}
\hline $\begin{array}{c}\text { Integration } \\
\text { starts at \# } \\
\begin{array}{c}\text { Log } \\
10 \\
\text { less than } \\
\text { the AEV }\end{array}\end{array}$ & $a_{f}=1 \mathrm{kPa}$ & $a_{f}=10 \mathrm{kPa}$ & $a_{f}=50 \mathrm{kPa}$ & $a_{f}=100 \mathrm{kPa}$ & $a_{f}=200 \mathrm{kPa}$ \\
\cline { 2 - 6 } & $0.107 \sim 10.424$ & $0.107 \sim 10.434$ & $0.110 \sim 10.495$ & $0.113 \sim 10.527$ & $0.124 \sim 10.521$ \\
\hline 10 & $0.107 \sim 4.418$ & $0.107 \sim 4.427$ & $0.109 \sim 4.487$ & $0.112 \sim 4.519$ & $0.119 \sim 4.512$ \\
\hline 4 & $0.107 \sim 2.367$ & $0.107 \sim 2.375$ & $0.109 \sim 2.425$ & $0.111 \sim 2.451$ & $0.117 \sim 2.443$ \\
\hline 2 & $0.107 \sim 1.262$ & $0.107 \sim 1.267$ & $0.109 \sim 1.301$ & $0.110 \sim 1.316$ & $0.114 \sim 1.309$ \\
\hline 1 & $0.107 \sim 0.659$ & $0.107 \sim 0.662$ & $0.108 \sim 0.681$ & $0.108 \sim 0.689$ & $0.110 \sim 0.683$ \\
\hline 0.5 & $0.106 \sim 0.272$ & $0.106 \sim 0.273$ & $0.106 \sim 0.281$ & $0.105 \sim 0.284$ & $0.104 \sim 0.281$ \\
\hline 0.2 & $0.091 \sim 0.137$ & $0.091 \sim 0.138$ & $0.090 \sim 0.142$ & $0.090 \sim 0.143$ & $0.089 \sim 0.142$ \\
\hline 0.1 & & & & & \\
\hline
\end{tabular}


Table 3. Range of the magnitude of the error in the estimation of permeability when the $m_{f}$ value changes from 0.5 to $4 .\left(n_{f}=2 ; \psi_{f}=2000 \mathrm{kPa}\right)$

\begin{tabular}{|c|c|c|c|c|}
\hline \multirow{2}{*}{$\begin{array}{c}\text { Integration starts at } \\
\text { \# } \begin{array}{c}\text { Log } \\
\text { than the AEV }\end{array}\end{array}$} & \multicolumn{3}{|c|}{ Error when $a_{f}$ is a designated value } \\
\cline { 2 - 5 } & $a_{f}=10 \mathrm{kPa}$ & $a_{f}=50 \mathrm{kPa}$ & $a_{f}=100 \mathrm{kPa}$ & $a_{f}=200 \mathrm{kPa}$ \\
\hline 10 & $0.317 \sim 0.323$ & $0.321 \sim 0.326$ & $0.325 \sim 0.339$ & $0.333 \sim 0.374$ \\
\hline 4 & $0.317 \sim 0.323$ & $0.320 \sim 0.324$ & $0.324 \sim 0.333$ & $0.331 \sim 0.353$ \\
\hline 2 & $0.317 \sim 0.322$ & $0.320 \sim 0.324$ & $0.323 \sim 0.330$ & $0.329 \sim 0.344$ \\
\hline 1 & $0.309 \sim 0.315$ & $0.311 \sim 0.316$ & $0.313 \sim 0.317$ & $0.317 \sim 0.324$ \\
\hline 0.5 & $0.262 \sim 0.270$ & $0.263 \sim 0.270$ & $0.264 \sim 0.271$ & $0.266 \sim 0.271$ \\
\hline 0.2 & $0.156 \sim 0.164$ & $0.156 \sim 0.164$ & $0.156 \sim 0.164$ & $0.156 \sim 0.164$ \\
\hline 0.1 & $0.090 \sim 0.096$ & $0.090 \sim 0.096$ & $0.090 \sim 0.096$ & $0.089 \sim 0.096$ \\
\hline
\end{tabular}




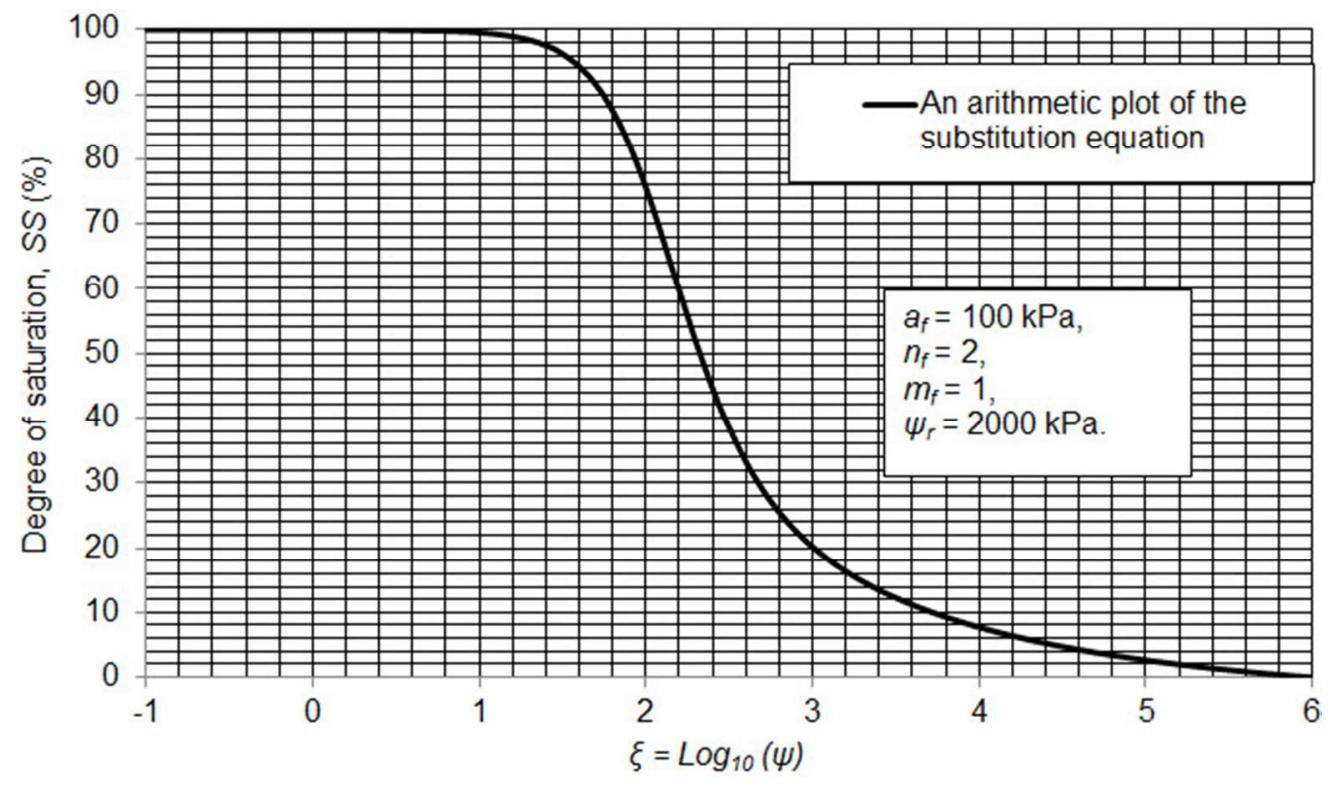

Figure 1. S-SWCC for a hypothetical soil plotted using semi-logarithmic coordinate

$177 \times 111 \mathrm{~mm}(96 \times 96$ DPI $)$ 


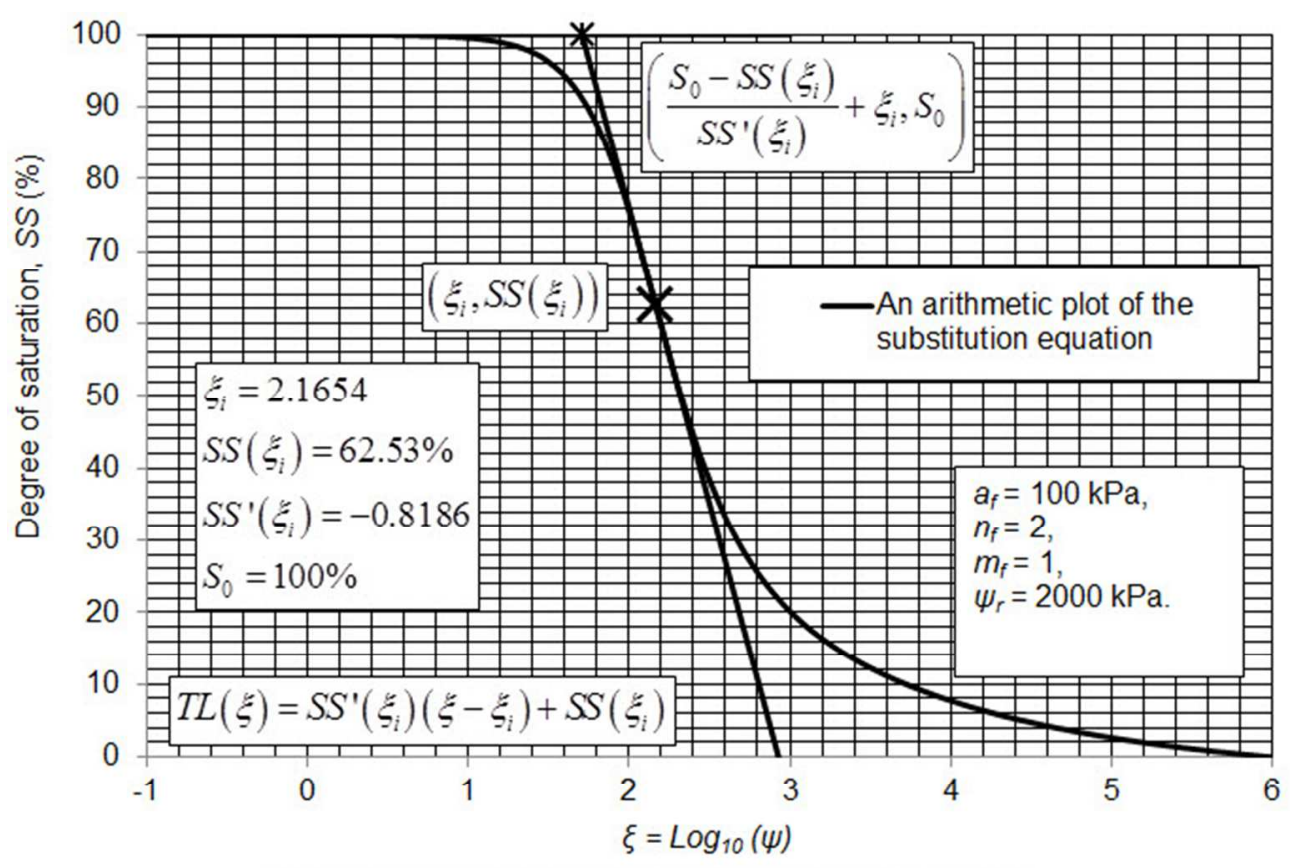

Figure 2. The arithmetical plot of the substitution equation

$182 \times 126 \mathrm{~mm}(96 \times 96 \mathrm{DPI})$ 


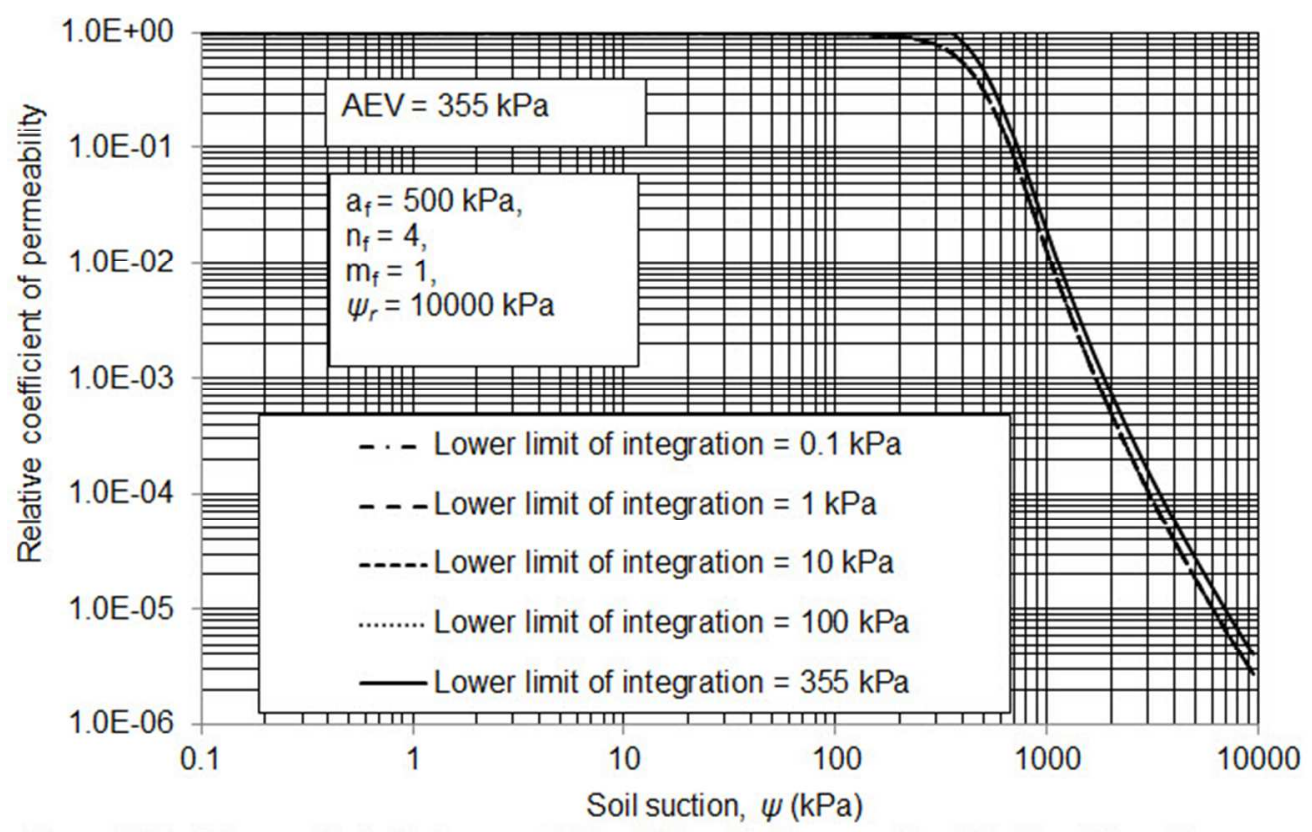

Figure 3. Relative coefficient of permeability obtained using equation (8) with different lower limits of integration for a soil with $a_{f}=500 \mathrm{kPa}, n_{f}=4, m_{f}=1, \psi_{r}=10000 \mathrm{kPa}$ for SWCC.

$180 \times 125 \mathrm{~mm}(96 \times 96 \mathrm{DPI})$ 


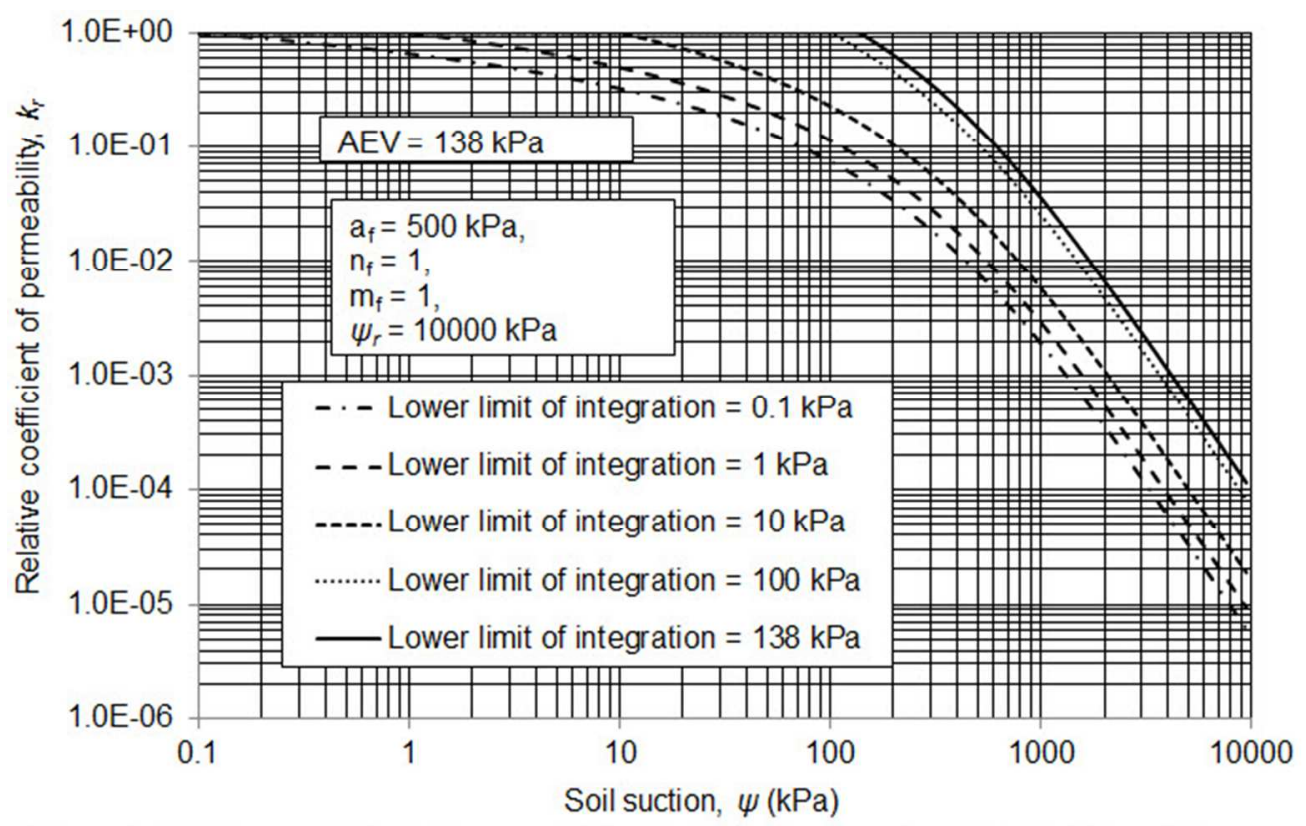

Figure 4. Relative coefficient of permeability obtained using equation (8) with different lower limits of integration for a soil with $a_{f}=500 \mathrm{kPa}, n_{f}=1, m_{f}=1, \psi_{r}=10000 \mathrm{kPa}$ for SWCC

$181 \times 126 \mathrm{~mm}(96 \times 96$ DPI $)$ 


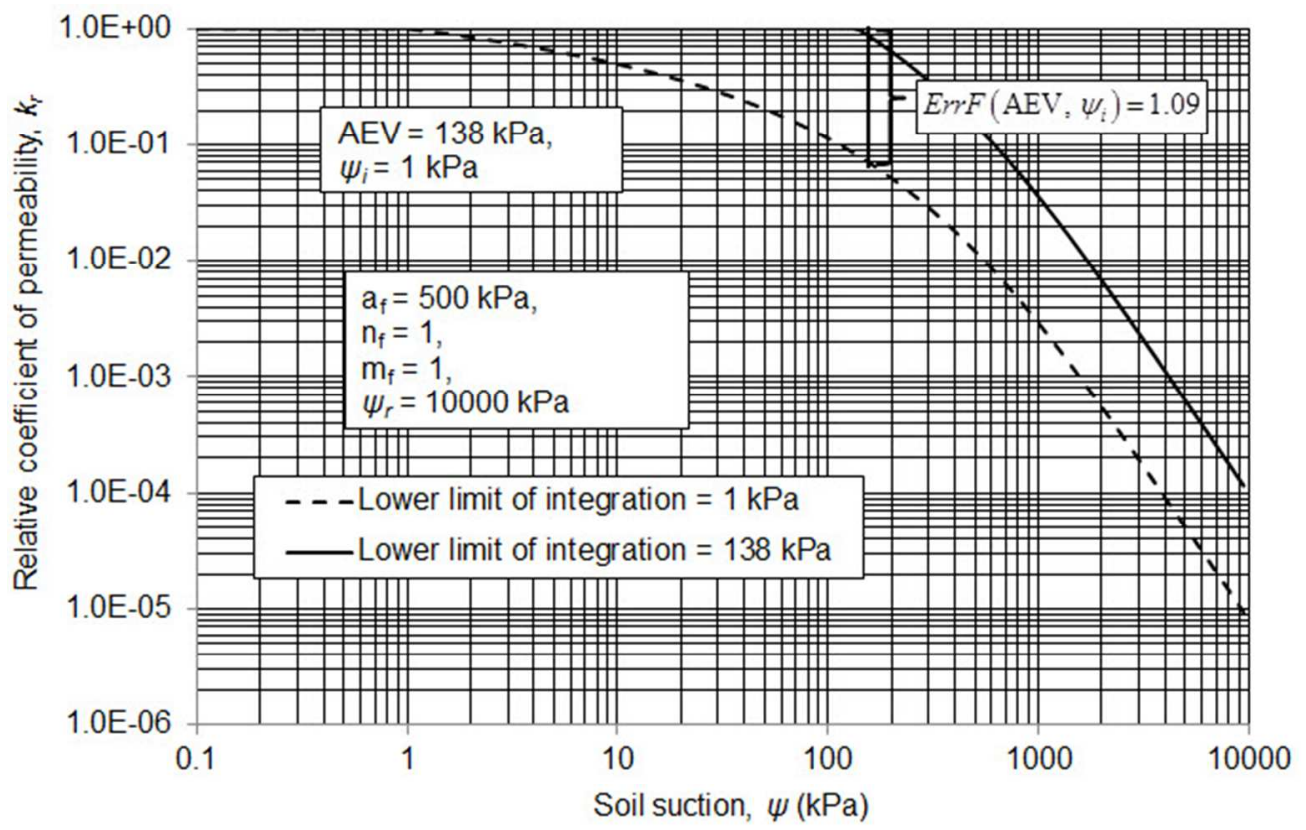

Figure 5. Error at AEV in terms of orders of magnitude caused by using $\psi_{i}$ equal to $1 \mathrm{kPa}$ as the lower limit of integration in equation (8).

$181 \times 127 \mathrm{~mm}(96 \times 96 \mathrm{DPI})$ 


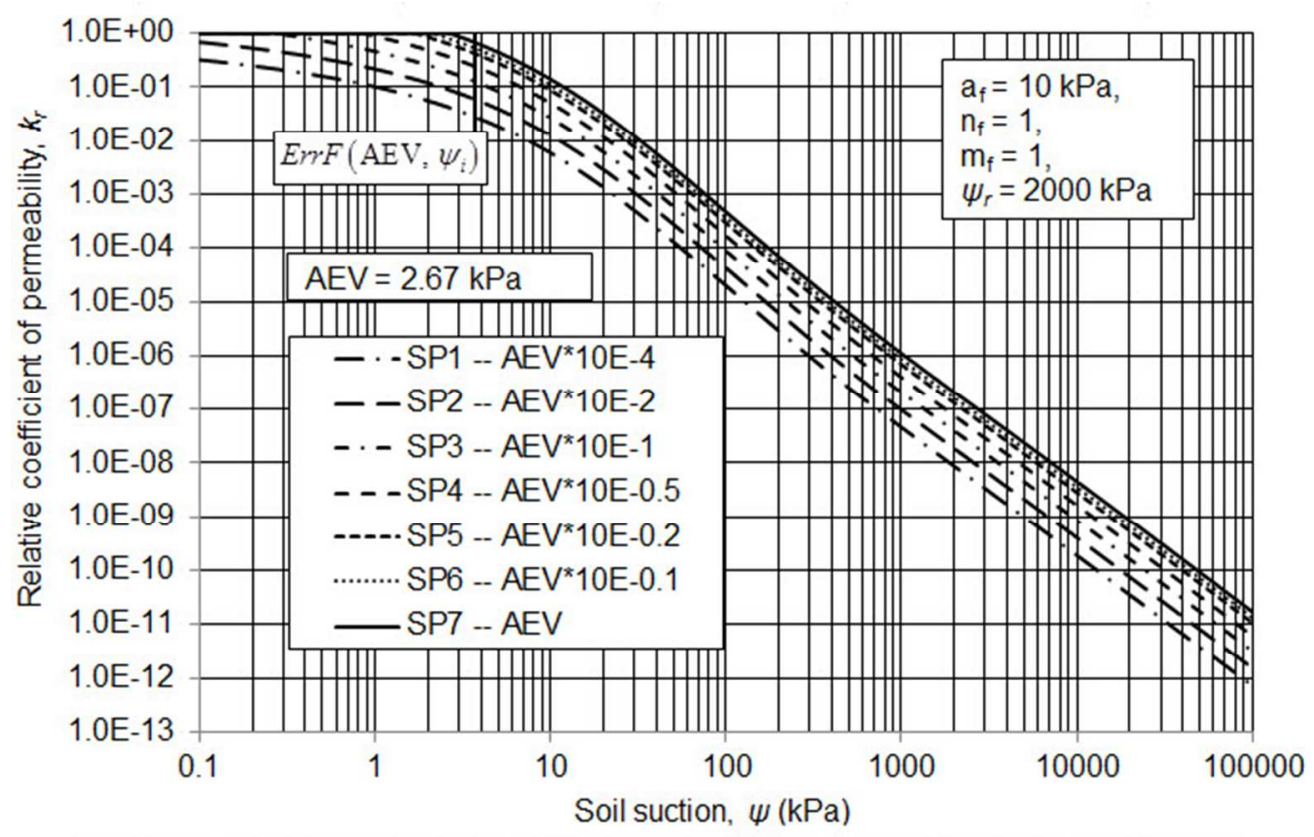

Figure 6 . The error in the estimation of the relative coefficient of permeability caused by various lower limits of integration $\left(a_{f}=10 \mathrm{kPa} ; n_{f}=1 ; m_{f}=1 ; \psi_{r}=2000 \mathrm{kPa}\right)$.

$180 \times 127 \mathrm{~mm}(96 \times 96 \mathrm{DPI})$ 


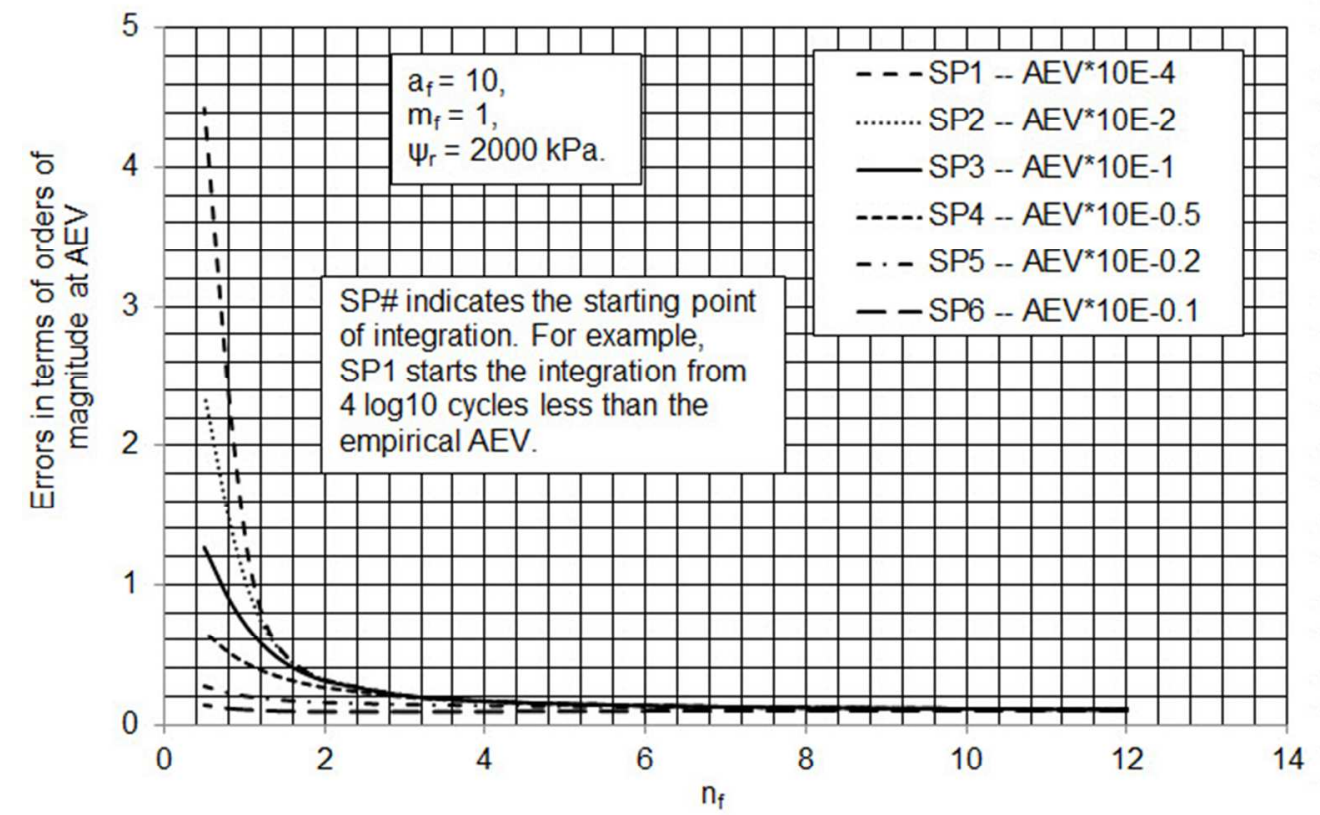

Figure 7. The influence of $n_{f}$ on the errors caused by using various lower limits of integration $\left(a_{f}=10 \mathrm{kPa} ; m_{f}=1 ; \psi_{r}=2000 \mathrm{kPa}\right)$.

$$
182 \times 126 \mathrm{~mm}(96 \times 96 \text { DPI })
$$




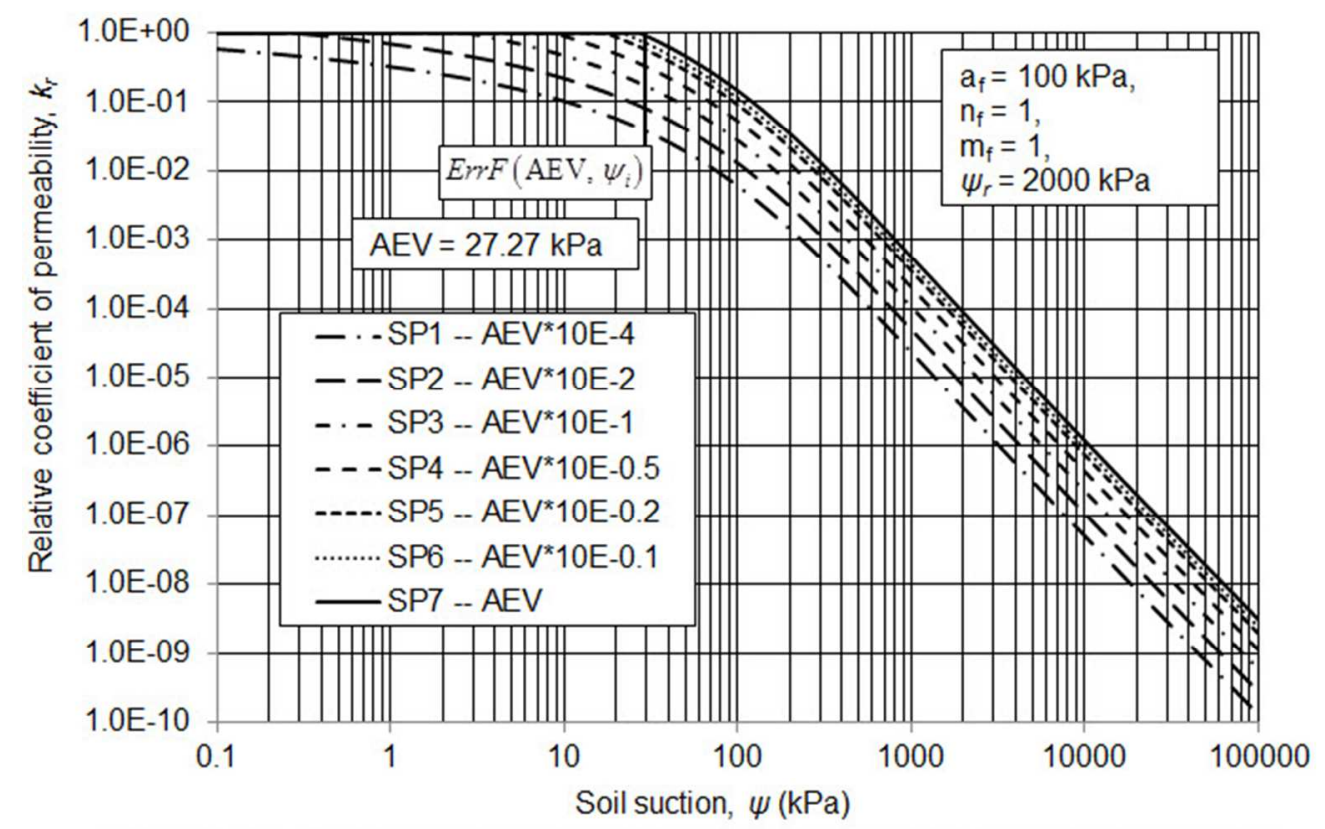

Figure 8 . The error in the estimation of the relative coefficient of permeability caused by various lower limits of integration $\left(a_{f}=100 \mathrm{kPa} ; n_{f}=1 ; m_{f}=1 ; \psi_{r}=2000 \mathrm{kPa}\right)$.

$181 \times 127 \mathrm{~mm}(96 \times 96 \mathrm{DPI})$ 


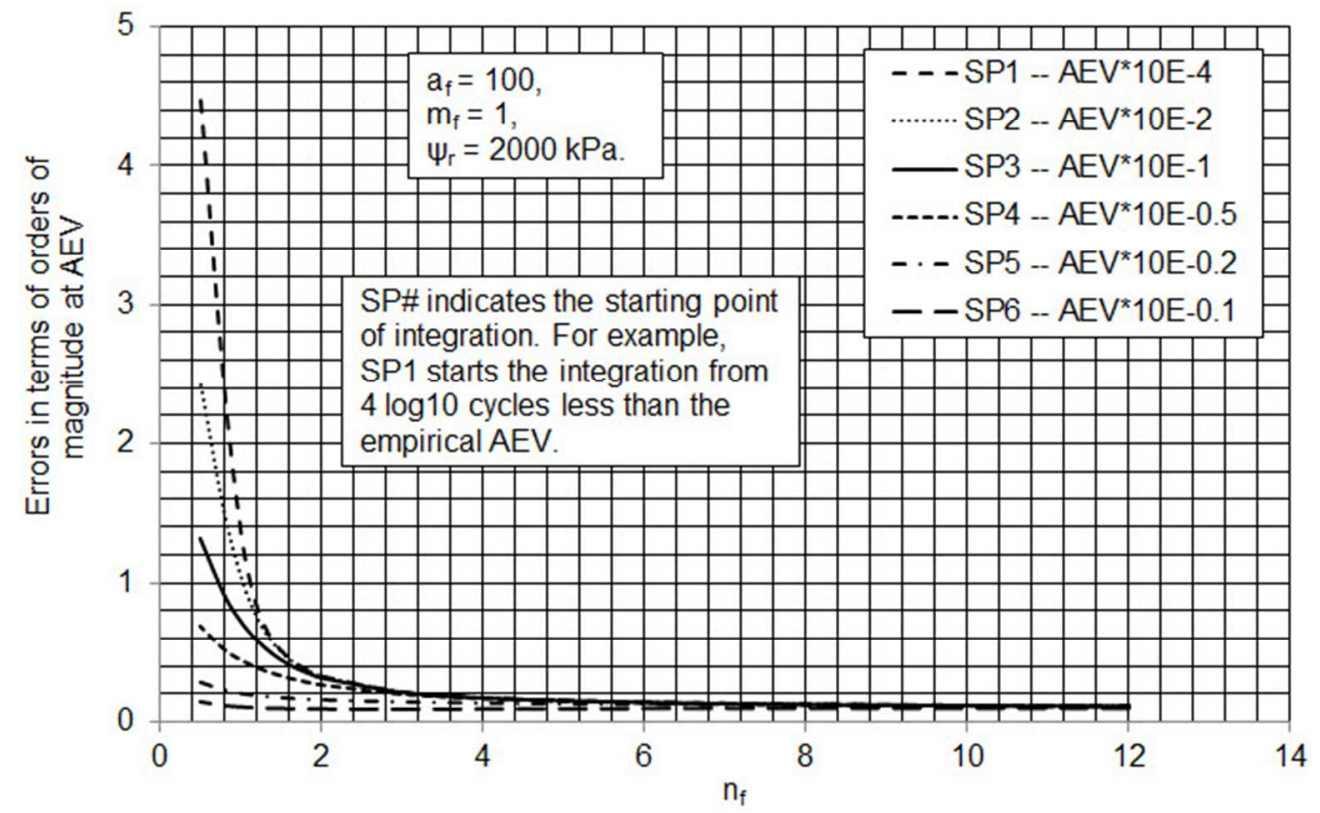

Figure 9. The influence of $n_{f}$ on the errors caused by using various lower limits of integration $\left(a_{f}=100 \mathrm{kPa} ; m_{f}=1 ; \psi_{r}=2000 \mathrm{kPa}\right)$.

$181 \times 127 \mathrm{~mm}(96 \times 96 \mathrm{DPI})$ 


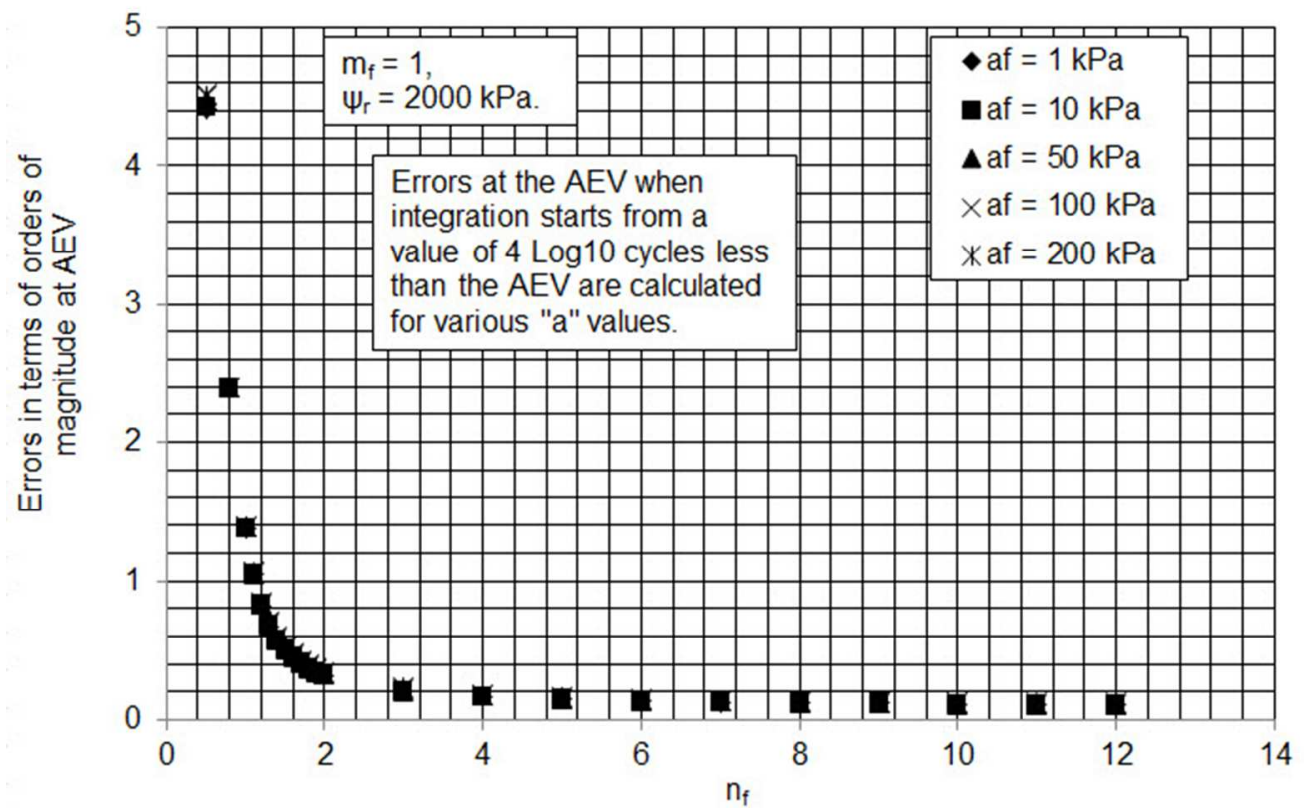

Figure 10. The influence of $n_{f}$ on the errors caused by using a low lower limit of integration of $4 \log _{10}$ cycles less than the AEV in cases of various $a_{f}$ values.

$182 \times 126 \mathrm{~mm}(96 \times 96 \mathrm{DPI})$ 


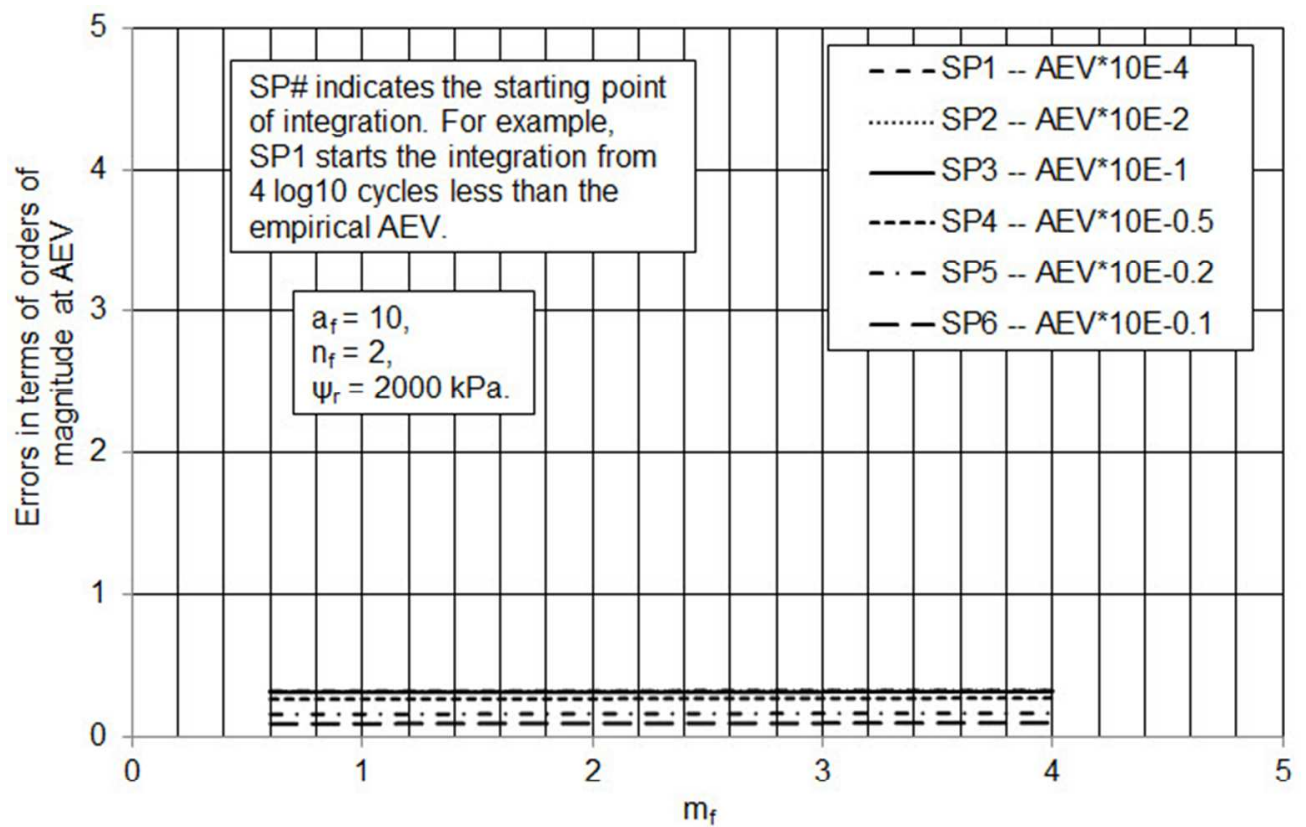

Figure 11. The influence of $m_{f}$ on the errors caused by using various lower limits of integration $\left(a_{f}=10 \mathrm{kPa} ; n_{f}=2 ; \psi_{r}=2000 \mathrm{kPa}\right)$.

$181 \times 126 \mathrm{~mm}(96 \times 96 \mathrm{DPI})$ 


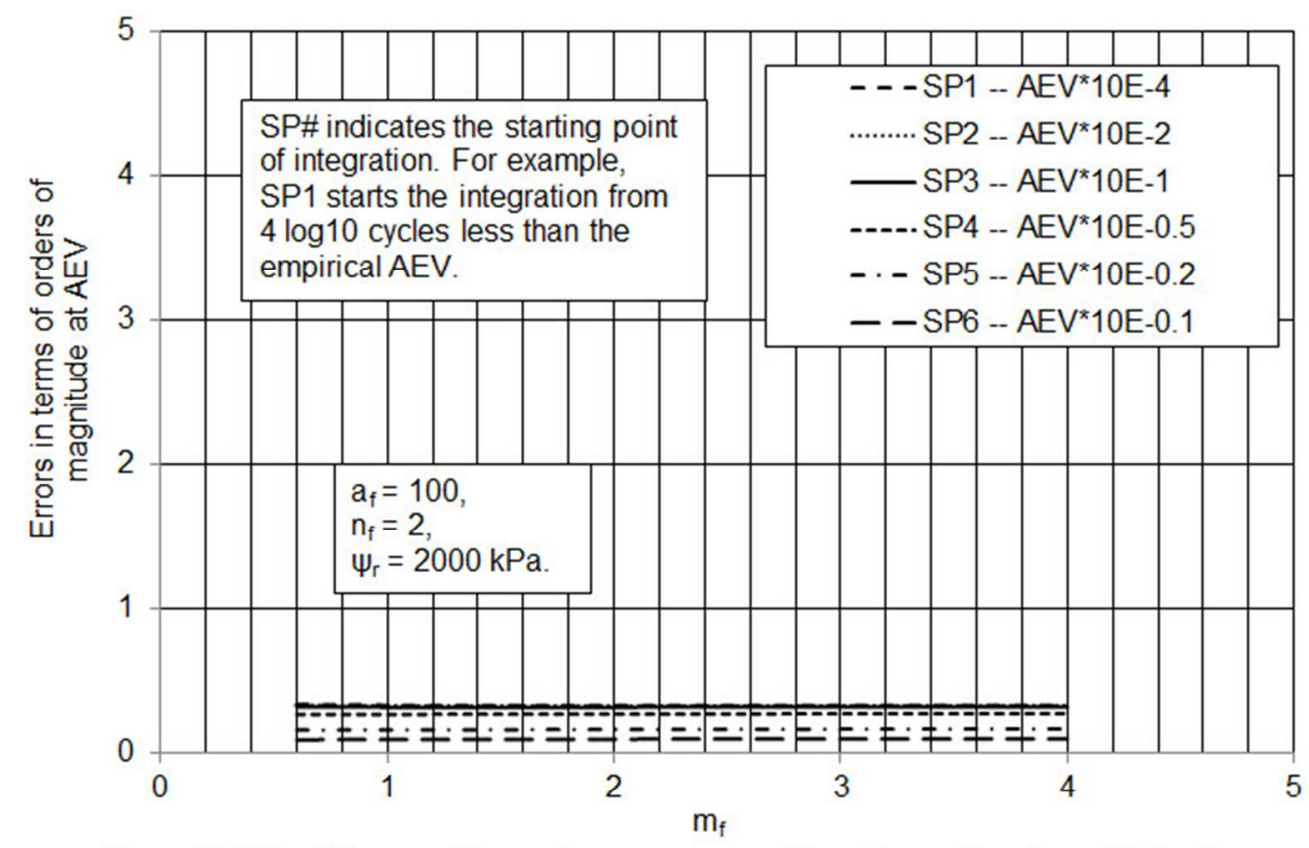

Figure 12. The influence of $m_{f}$ on the errors caused by using various lower limits of integration $\left(a_{f}=100 \mathrm{kPa} ; n_{f}=2 ; \psi_{r}=2000 \mathrm{kPa}\right)$.

$181 \times 126 \mathrm{~mm}(96 \times 96 \mathrm{DPI})$ 


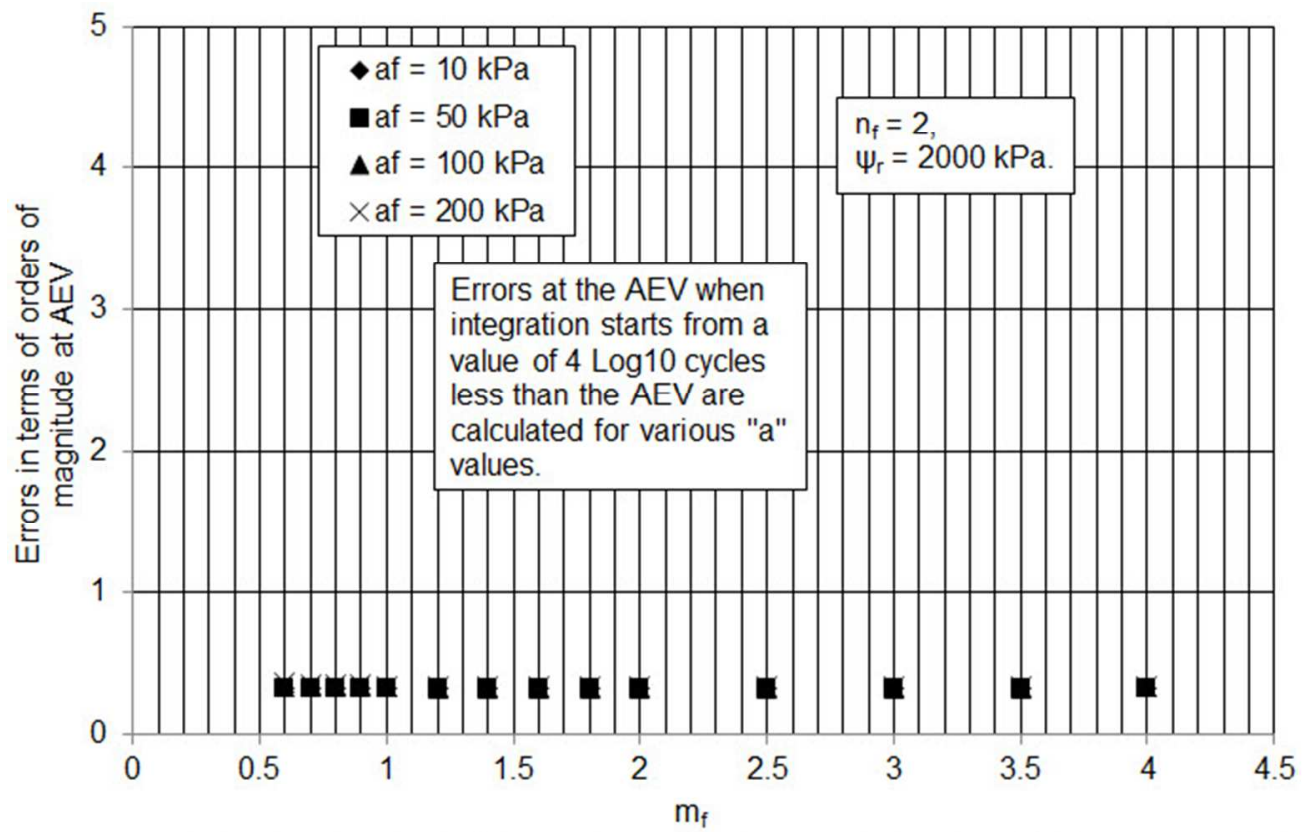

Figure 13. The influence of $m_{f}$ on the errors caused by using a low lower limit of integration of $4 \log _{10}$ cycles less than the AEV in cases of various $a_{f}$ values.

$181 \times 127 \mathrm{~mm}(96 \times 96 \mathrm{DPI})$ 